\title{
Capsaicin 8\% patch treatment for amputation stump and phantom limb pain: a clinical and functional MRI study
}

This article was published in the following Dove Press journal:

Journal of Pain Research

13 July 2017

Number of times this article has been viewed

\author{
Rosario Privitera' \\ Rolfe Birch' \\ Marco Sinisi \\ lordan R Mihaylov ${ }^{3}$ \\ Robert Leech ${ }^{4}$ \\ Praveen Anand
}

'Peripheral Neuropathy Unit, Centre for Clinical Translation, Hammersmith Hospital, Imperial College London, London, UK; ' ${ }^{2}$ Peripheral Nerve Injury Unit, Royal National Orthopaedic Hospital, Stanmore, Middlesex, UK; ${ }^{3}$ Department of Pain Medicine, Royal National Orthopaedic Hospital NHS Trust, Stanmore, UK; ${ }^{4}$ Computational, Cognitive and Clinical Neuroimaging Laboratory, Division of Brain Sciences, Imperial College London, Hammersmith Hospital Campus, London, UK
Correspondence: Praveen Anand Peripheral Neuropathy Unit, Imperial College London, Hammersmith Hospital, Du Cane Rd, London WI2 ONN, UK

Tel +44208383 3319

Fax +44208383 3363

Email p.anand@imperial.ac.uk
Purpose: The aim of this study was to measure the efficacy of a single $60 \mathrm{~min}$ application of capsaicin $8 \%$ patch in reducing chronic amputation stump and phantom limb pain, associated hypersensitivity with quantitative sensory testing, and changes in brain cortical maps using functional MRI (fMRI) scans.

Methods: A capsaicin 8\% patch (Qutenza) treatment study was conducted on 14 patients with single limb amputation, who reported pain intensity on the Numerical Pain Rating Scale $\geq 4 / 10$ for chronic stump or phantom limb pain. Pain assessments, quantitative sensory testing, and fMRI (for the lip pursing task) were performed at baseline and 4 weeks after application of capsaicin $8 \%$ patch to the amputation stump. The shift into the hand representation area of the cerebral cortex with the lip pursing task has been correlated with phantom limb pain intensity in previous studies, and was the fMRI clinical model for cortical plasticity used in this study. Results: The mean reduction in spontaneous amputation stump pain, phantom limb pain, and evoked stump pain were -1.007 ( $p=0.028),-1.414$ ( $p=0.018)$, and $-2.029(p=0.007)$, respectively. The areas of brush allodynia and pinprick hypersensitivity in the amputation stump showed marked decreases: $-165 \mathrm{~cm}^{2},-80 \%(p=0.001)$ and $-132 \mathrm{~cm}^{2},-72 \%(p=0.001)$, respectively. fMRI analyses provided objective evidence of the restoration of the brain map, that is, reversal of the shift into the hand representation of the cerebral cortex with the lip pursing task $(p<0.05)$. Conclusion: The results show that capsaicin $8 \%$ patch treatment leads to significant reduction in chronic pain and, particularly, in the area of stump hypersensitivity, which may enable patients to wear prostheses, thereby improving mobility and rehabilitation. Phantom limb pain ("central" pain) and associated brain plasticity may be modulated by peripheral inputs, as they can be ameliorated by the peripherally restricted effect of the capsaicin $8 \%$ patch.

Keywords: amputation, phantom limb pain, capsaicin, fMRI

\section{Introduction}

Following limb amputation, more than $50 \%$ patients complain of hypersensitivity in the amputation stump and chronic pain, which may be reported in both the residual limb and the area referred to the body part removed. ${ }^{1-3}$ The pain referred to a missing $\operatorname{limb} b^{4}$ or an organ ${ }^{5-12}$ is termed phantom pain. Chronic pain has a negative impact on quality of life, aggravating psychologic distress following the amputation ${ }^{13}$ and increasing the risk of developing anxiety and depression. ${ }^{14}$ Moreover, stump pain may worsen on walking, ${ }^{15,16}$ which affects the use of a prosthesis and rehabilitation. ${ }^{17}$

Several studies have reported factors that may be related to the risk of developing chronic pain following an amputation - time elapsed since amputation, ${ }^{18}$ presence of pain before amputation, ${ }^{19}$ higher levels of pain soon after amputation, ${ }^{20}$ psychologic 
factors, ${ }^{21}$ intensity of concomitant nonpainful phantom limb sensations, ${ }^{22}$ and the site of amputation. ${ }^{23}$ Objective methods have demonstrated changes in both the peripheral and central nervous systems, including neuroimaging and neurophysiologic techniques, in patients with chronic phantom pain after an amputation. Maladaptive plasticity has been suggested as an underlying mechanism for chronic pain, from observations in patients who showed spread of activation from the neighboring cortical areas into the deprived cortical area. ${ }^{24}$ This spread or shift into the deprived cortical area, for example, with the lip pursing task, was positively correlated with the presence and intensity of the phantom limb pain. ${ }^{25-27}$

The act of lip pursing was used in our study, during the functional magnetic resonance imaging (fMRI) assessment, to evoke brain activation. This method was used previously by Lotze et al, ${ }^{27}$ and consisted of a simple lip pursing movement performed every second (rate of $1 \mathrm{~Hz}$ ) during fMRI acquisition. The scanning paradigm consisted of a run of alternating resting and stimulation (lip pursing) blocks. Each block was initiated and terminated by a "go" and "stop" command.

Many pharmacologic and nonpharmacologic strategies have been considered for reversing the maladaptive plasticity, and recent studies have shown return toward a more normal cortical activation pattern after the restoration of the peripheral function, such as targeted reinnervation ${ }^{28}$ and hand transplantation. ${ }^{29}$ Huse et al, ${ }^{30}$ in a small study conducted in patients with phantom and stump pain who received morphine, showed both decrease in pain and changes in cortical maps in three patients, which were correlated with the decrease in pain intensity.

Randomized clinical trials in chronic phantom limb pain have focused mainly on the drugs used for neuropathic pain. ${ }^{31}$ Maier et $\mathrm{al}^{32}$ conducted a trial of the $N$-methyl-D-aspartic acid-receptor antagonist Memantine, which did not show any beneficial effect on phantom limb pain. In one study, Gabapentin was more effective than placebo in controlling phantom limb pain; ${ }^{33}$ however, another similar study did not show significant difference versus placebo. ${ }^{34}$ Treatment with Amitriptyline failed to provide pain relief in a placebocontrolled study. ${ }^{35}$ In another clinical trial, ${ }^{36}$ Amitriptyline and Tramadol produced a minor decrease in pain.

Many authors have reported the efficacy, ${ }^{37-47}$ safety, and tolerability ${ }^{46,48-53}$ of a single application of capsaicin $8 \%$ patch (Qutenza), a high-dose topical formulation for the treatment of peripheral neuropathic pain. Capsaicin, the pungent "hot" ingredient in chili peppers, is a natural selective agonist of the vanilloid receptor TRPV1. It is released rapidly from the capsaicin $8 \%$ patch, and leads to overstimulation of the skin
TRPV1 nociceptors which are "defunctionalized" and are no longer able to respond to the stimuli that normally cause pain in patients with peripheral neuropathic pain. ${ }^{54} \mathrm{~A}$ single application of capsaicin $8 \%$ patch can provide pain relief for up to 3 months or more, ${ }^{37-47}$ without the systemic side effects seen with other pain treatments, ${ }^{46,48-53}$ with the maximum effect reached within 1-2 weeks from the application. ${ }^{54}$ Capsaicin $8 \%$ patch has been shown in a previous study to reduce the intensity of amputation stump and phantom limb pain, ${ }^{55}$ but sensory and brain mechanisms have not been studied.

The aim of this study was to measure the analgesic effect of a single application of capsaicin $8 \%$ patch and the associated changes with quantitative sensory tests in the amputation stump. An additional aim was to investigate plasticity of brain maps with the lip pursing task, using fMRI scans.

\section{Materials and methods}

This was an open-label, longitudinal study in patients with amputation stump and phantom limb pain, using the capsaicin 8\% patch (Qutenza) treatment as licensed. The study was conducted at Hammersmith Hospital, Imperial College London and Imperial College NHS Trust, in collaboration with colleagues at the Royal National Orthopaedic Hospital, Stanmore. The study was approved by the Charing Cross Research Ethics Committee, London (NRES Committee London - Fulham; REC reference: 15/LO/0566), and each subject provided written informed consent. This was an investigator-led study sponsored by Imperial College London.

The study duration for each patient was 4 weeks, including three hospital visits and telephone calls as shown in Figure 1. At the screening visit, patients were given a trial pain diary to complete for the next 7 days. The diary collected numerical pain rating score (NPRS) twice daily (ranging from 0 to 10), as the average pain over the last $12 \mathrm{~h}$. An 11-point numerical rating scale (NPRS) with the 0 anchor point being "no pain" and the 10 anchor point being "pain as bad as you can imagine" was used to separately record spontaneous stump pain, evoked stump pain, and phantom limb pain. Patients with average pain intensity equal or greater than $4 / 10$ for spontaneous stump or phantom limb pain, and who had been clinically stable on their prescribed medical treatment for a period $\geq 2$ months, were eligible to participate further in the study. They were advised to continue with trial pain diary daily for the entire duration of the study until the endof-study follow-up visit. All tests (Visit 1 and Visit 3) were carried out before and after a single 60 min capsaicin $8 \%$ patch application (Visit 2; Figure 1). The patch application was performed as licensed and provided as a treatment in 


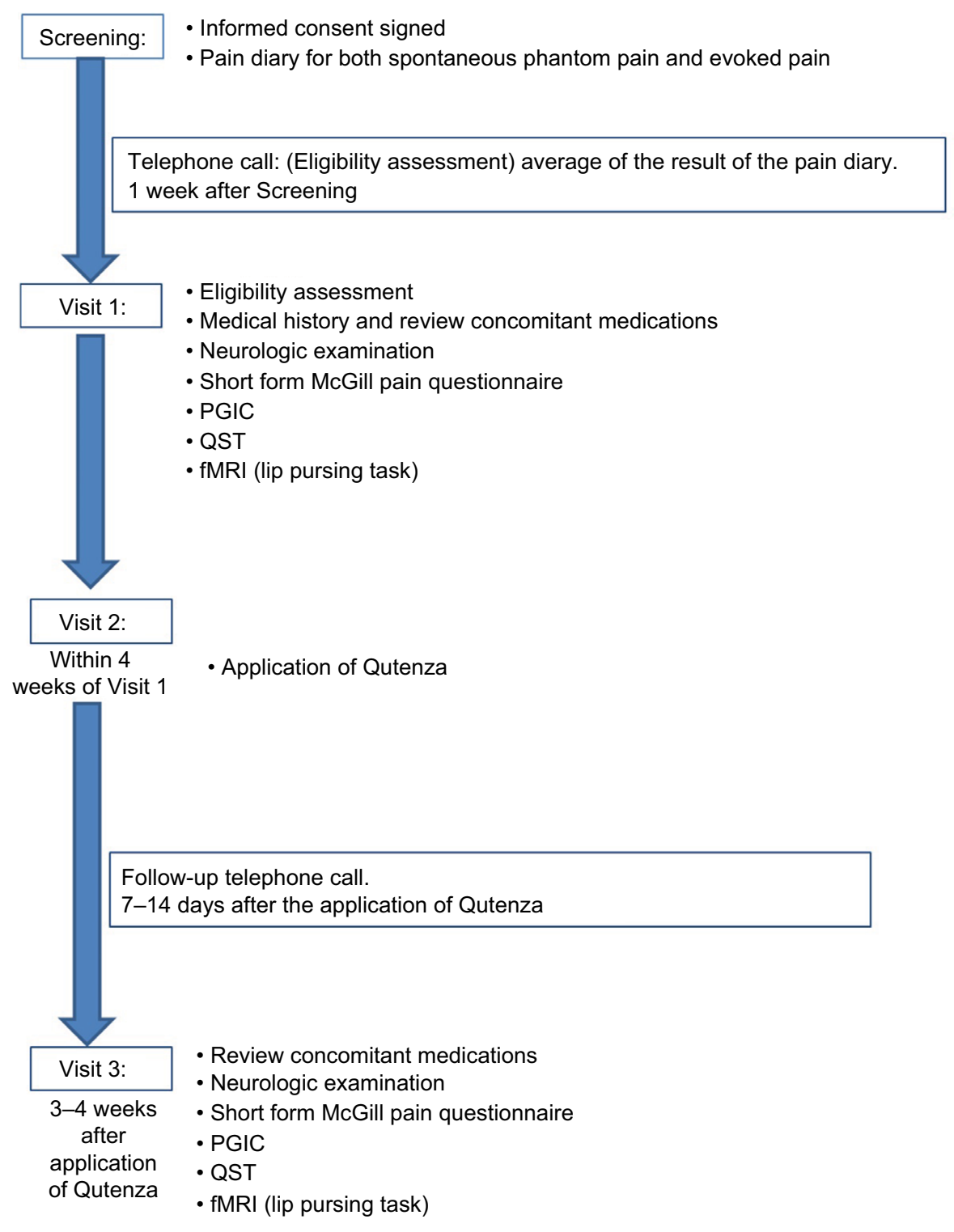

Figure I Study design flow diagram.

Abbreviations: fMRI, functional magnetic resonance imaging; PGIC, Patient Global Impression of Change; QST, quantitative sensory testing.

pain clinics. The capsaicin $8 \%$ patch is a $14 \times 20 \mathrm{~cm}\left(280 \mathrm{~cm}^{2}\right)$ patch containing a high dose of capsaicin (Figure 2). Each patch application delivers $179 \mathrm{mg}$ capsaicin directly into the skin. Nitrile gloves were worn at all times while handling the patch and cleaning the treatment area. Before treatment, the
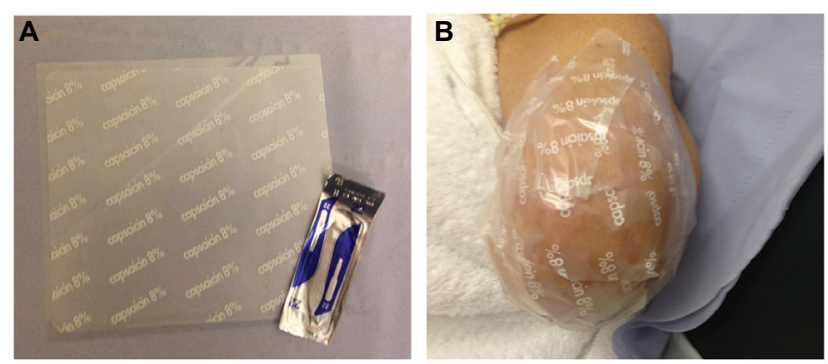

Figure 2 Capsaicin $8 \%$ patch application.

Note: The capsaicin $8 \%$ patch $(\mathbf{A})$ and patch application to the affected stump area (B). skin was washed and dried. Hairs were clipped to promote patch adherence. The capsaicin $8 \%$ patch was cut with a scalpel prior to removal of the release liner and shaped over the surface of the stump, which was unique for each patient. The application of the patch was on intact, nonirritated, and dry skin. The patch was kept firmly in contact with the skin for $1 \mathrm{~h}$ (Figure 2). The patch was then carefully removed, cleaning gel applied for $1 \mathrm{~min}$, and the skin washed and dried.

\section{Patients}

Between 2015 and 2016, six male and eight female patients with single limb amputation were studied. The patient cohort included five with upper limb and nine lower limb amputations. The average age of subjects was 53 years (Table 1 ). Eight patients had amputation involving the knee joint; one 
Table I Clinical characteristics of patients in the study

\begin{tabular}{|c|c|c|c|c|c|c|}
\hline Patient & Level of amputation & $\begin{array}{l}\text { Phantom pain } \\
\text { (NPRS) }\end{array}$ & $\begin{array}{l}\text { Stump pain } \\
\text { (NPRS ) }\end{array}$ & Medications & $\begin{array}{l}\text { Time since the } \\
\text { amputation (months) }\end{array}$ & $\begin{array}{l}\text { Duration of pain } \\
\text { (months) }\end{array}$ \\
\hline \multirow[t]{5}{*}{1} & AEA & 6.6 & 5.5 & GBP & 420 & 420 \\
\hline & & & & CLZ & & \\
\hline & & & & QHCL & & \\
\hline & & & & OXY & & \\
\hline & & & & FEN & & \\
\hline 2 & Wrist disarticulation & 6.4 & 6 & DLX & 48 & 47 \\
\hline \multirow[t]{2}{*}{3} & BEA & 7 & 7 & MS & 96 & 48 \\
\hline & & & & OXY & & \\
\hline 4 & BKA & 0 & 7.6 & GBP & 156 & 108 \\
\hline \multirow[t]{3}{*}{5} & AEA & 7.6 & 7.3 & DLX & 72 & 72 \\
\hline & & & & Tapentadol & & \\
\hline & & & & PGB & & \\
\hline \multirow[t]{2}{*}{6} & TFA & 2.8 & 5 & PGB & 24 & 24 \\
\hline & & & & COD & & \\
\hline \multirow[t]{2}{*}{7} & BKA & 7.8 & 7.5 & MS & 120 & 120 \\
\hline & & & & NPT & & \\
\hline 8 & Finger amputation & 1.4 & 4 & - & 12 & 84 \\
\hline \multirow[t]{6}{*}{9} & Pelvic amputation & 5.6 & 6.2 & $\mathrm{IBU}$ & 36 & 60 \\
\hline & & & & PGB & & \\
\hline & & & & MS & & \\
\hline & & & & PCM & & \\
\hline & & & & SER & & \\
\hline & & & & ZOP & & \\
\hline \multirow[t]{4}{*}{10} & AKA & 5.2 & 5.8 & PGB & 60 & 60 \\
\hline & & & & $\mathrm{LT}$ & & \\
\hline & & & & IBU & & \\
\hline & & & & CBZ & & \\
\hline II & BKA & 7.2 & 6.9 & PGB & 108 & 120 \\
\hline \multirow[t]{3}{*}{12} & BKA & 8.8 & 3 & PGB & 24 & 84 \\
\hline & & & & OXY & & \\
\hline & & & & PCM & & \\
\hline \multirow[t]{3}{*}{13} & BKA & 8 & 7.8 & ATP & 36 & 36 \\
\hline & & & & Tapentadol & & \\
\hline & & & & PCM & & \\
\hline \multirow[t]{2}{*}{14} & AKA & 5 & 0 & GBP & 108 & 132 \\
\hline & & & & MS & & \\
\hline
\end{tabular}

Abbreviations: AEA, above elbow amputation; AKA, above knee amputation; ATP, amitriptyline; BEA, below elbow amputation; BKA, below knee amputation; CBZ, clobazam; CLZ, clonazepam; COD, codeine; DLX, duloxetine; FEN, fentanyl; GBP, gabapentin; IBU, ibuprofen; LT, levothyroxine; MS, morphine sulfate; NPRS, numerical pain rating score; NPT, Nortriptyline; OXY, oxycodone; PCM, paracetamol; PGB, pregabalin; QHCL, quinine hydrochloride; SER, sertraline; TFA, transfemoral amputation; ZOP, zopiclone.

had an amputation at the hind quarter level, one had a right middle finger amputation, three had an amputation at the elbow joint and one at the wrist joint. Ten amputations were traumatic, two followed a long history of chronic pain due to orthopedic problems, and two were performed because of the presence of cancer. Time since patients had the amputation ranged from 12 to 420 months (35 years), with an average of 94 months ( 7.8 years). The mean number (range) of capsaicin patches applied during the study was $1.5(1-2)$ patches.

\section{Clinical symptoms and pain scores}

Patients described a range of symptoms, most commonly as pins and needles, tenderness of the stump, electric shocks, crushing, cold-freezing, shooting, stabbing, and burning pain. Many patients reported vivid phantom sensations. Eight patients described the missing limb with an abnormal shape, and three with an increased volume and size. All patients enrolled in the study were taking treatment for neuropathic pain at the start of the study, such as Gabapentin, Pregabalin, Duloxetine, tricyclic antidepressants, Oxycodone, Morphine, or a combination of these. Patients maintained their concomitant medications throughout the study. Details of the patients at baseline are reported in Table 1.

\section{Clinical examination}

At the initial visit, a detailed medical history was taken from the subject and the procedures were explained. Each subject was asked to describe the perceived size, shape, movement, 
and any other qualities of the phantom limb, as well as the location, quality, and frequency of stump and phantom pain. Clinical examination and tests were performed in both amputated and contralateral limb. Vibration, monofilament, and thermal thresholds were performed as described below. Symptoms were recorded using the short-form McGill Pain Questionnaire ${ }^{56}$ (maximum score 55, indicating severe symptoms) and by recording a numerical pain score (Likert pain score: $0=$ no pain; $10=$ maximum pain). Patients were also asked to complete a seven-point scale (Patient Clinical Global Impression of Change) before and after the treatment - as no change, improved, or worse..$^{57,58}$

\section{Quantitative sensory testing}

Vibration perception thresholds were measured using a biothesiometer (Biomedical Instrument Company, Newbury, $\mathrm{OH}$, USA) placed over a distal bony prominence. Three ascending and three descending trials were carried out, and the mean value obtained. Values $>12 \mathrm{~V}$ were considered abnormal. ${ }^{59,60}$

The thresholds for light touch were measured using monofilaments made by $\mathrm{Mr}$ A Ainsworth, University College London, UK (No. 1, $0.0174 \mathrm{~g}$ to No. 20, $263.0 \mathrm{~g}$ ). The number of the hair with the lowest force reliably detected by the patient at the center of the area of hypersensitivity was recorded. Values $>$ No. 3 monofilament $(0.0479 \mathrm{~g})$ were considered abnormal. ${ }^{59}$ The monofilament with the lowest force that caused pain or discomfort was also recorded. Clinical examination was carried out along the stump on its entire circumference from the distal end, to determine the area of any static (monofilament) and dynamic (brush) allodynia and also pinprick hypersensitivity. This method was used to obtain a detailed map before the application of capsaicin $8 \%$ patch, in order to localize the area requiring the treatment.

Static allodynia area was determined by a monofilament at the touch detection threshold in the contralateral intact limb, and the area of dynamic allodynia by gently stroking with a standardized brush (yellow brush; Somedic, Stockholm, Sweden). Allodynia was considered present if the sensation changed from a feeling of touch to a sensation of pain or discomfort. For pinprick testing, the sharp and dull ends of a sterile Neurotip pin were first lightly applied to the limb. The subject responded "sharp" or "dull" when the respective stimulus was detected. The surface area of increased or decreased pinprick sensation over the stump was mapped by moving the pin along the stump. Patients were asked to rate the evoked sensation as normal, diminished, absent, or increased, increased abnormal, and increased painful. The outline of both areas of allodynia and pinprick hyper- sensitivity was traced onto a transparent plastic sheet and transferred to metric graph paper. ${ }^{61}$ The area obtained after the examination was calculated by the weighing method ${ }^{62}$ using a Sartorius balance.

Thermal perception thresholds were performed as described $^{63,64}$ using the TSA-II NeuroSensory Analyzer (Medoc, Ramat Yishai, Israel). A $30 \times 30 \mathrm{~mm}$ thermode was used, and thermal thresholds were determined in the center of the affected area for warm perception, cool perception, heat pain, and cold pain, from a baseline temperature of $32^{\circ} \mathrm{C}$, with a change in temperature of $1^{\circ} \mathrm{C} / \mathrm{s}$. All measurements were performed by placing the thermode in an area away from the scar tissue. The mean of three consecutive tests for each modality was recorded. Values $>6.4^{\circ} \mathrm{C}$ for warm sensation, $>2.3^{\circ} \mathrm{C}$ for cool sensation, and $>10.4^{\circ} \mathrm{C}$ for heat pain were considered abnormal, but variation with aging was noted. ${ }^{59,63,64}$ Thermal thresholds were obtained from the distal site of the anterior aspect of the stump. ${ }^{65}$ Sensory testing was repeated at the follow-up visit in the amputated limb and at a similar site in the intact limb. ${ }^{65,66}$

\section{Functional magnetic resonance imaging}

Patients were scanned twice while performing a lip pursing motor task, once prior to and once posttreatment. Patients were visually cued to perform the task in blocks of $30 \mathrm{~s}$ of lip pursing or resting. There were six blocks of rest and six blocks of lip pursing. The scanning protocol included a high-resolution gradient-echo T1-weighted structural anatomic volume (for registration between patients; voxel size: $1.00 \times 1.00 \times 1.00 \mathrm{~mm}$, flip angle: $9^{\circ}$, repetition time $[\mathrm{TR}] /$ echo time: $2300 / 2.98 \mathrm{~ms}, 160$ ascending slices, inversion time: $900 \mathrm{~ms}$ ) acquired on a Siemens Verio $3 \mathrm{~T}$ scanner, as well as an Echo Planar Imaging (EPI) sequence (182 volumes of T $2 *$-weighted gradient echo, voxel size: $3.00 \times 3.00 \times 3.00$ $\mathrm{mm}$, field of view: $192 \times 192 \times 105 \mathrm{~mm}$, flip angle: $80^{\circ}, \mathrm{TR} /$ echo time: $2000 / 30 \mathrm{~ms}, 35$ interleaved slices with $3.00 \mathrm{~mm}$ thickness). Each run lasted 182 TR. Data analysis was carried out with FSL (FMRIB Software Library): ${ }^{67} 1$ ) brain extraction of the anatomic image; ${ }^{68}$ 2) linear registration of the anatomic image (using 12 degrees of freedom) to a standard $2 \mathrm{~mm}$ brain atlas (Montreal Neurological Institute [MNI]) using FLIRT (FMRIB's Linear Image Registration Tool); ${ }^{69}$ 3 ) the functional data were registered to the anatomic image using FLIRT BBR (FMRIB's Linear Image Registration Tool, Boundary-Based Registration); 4) the functional images were corrected using Motion Correction Linear Image Registration Tool (MCFLIRT); 5) functional images were high-pass 
filtered with a cutoff of $60 \mathrm{~s}$; and 6) spatially smoothed using a $5 \mathrm{~mm}$ full width at half maximum Gaussian kernel.

Data were analyzed by convolving a canonical doublegamma hemodynamic response function with the task (30 s ON/OFF) time course. First and second scans were contrasted (First $>$ Second) using a fixed-effect model for each patient. Subsequently, bilateral regions of interest were defined in group space for approximately the lip area (centered on MNI 52-8 36) and the hand area (centered on MNI 28-20 62) of the motor cortex and the estimated change in task-evoked blood oxygen level dependent (BOLD) signal extracted for each ROI. The signal change (First session Second session) on the contralateral side to the amputation was then subtracted from the signal change on the ipsilateral side. One patient who did not respond to the treatment was not included in the subsequent analyses.

\section{Statistical analysis}

Data were analyzed using GraphPad Prism version 5.0 for Windows (GraphPad Prism Software, San Diego, CA, USA). The statistical test used was the paired, two-tailed MannWhitney test. Values were compared before and after the treatment with capsaicin $8 \%$ patch. For all statistical tests, $p$ values $<0.05$ were considered significant.

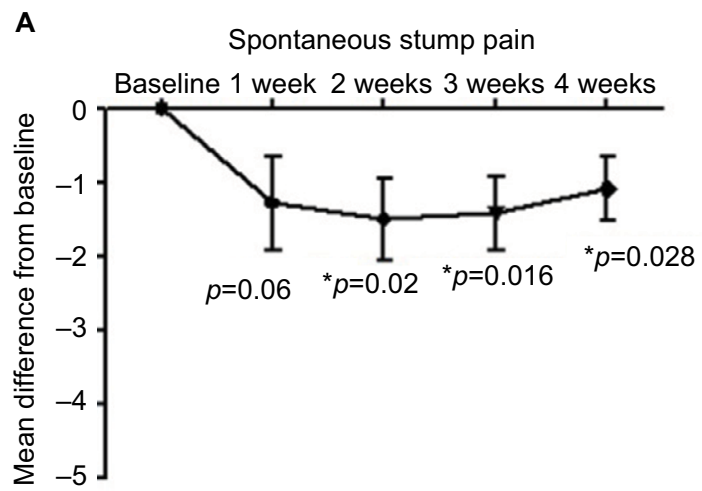

\section{Results}

\section{Clinical symptoms and pain scores}

Patients $(\mathrm{N}=14)$ reported baseline NPRS scores (mean $\pm \mathrm{SD}$ ) for spontaneous stump pain and evoked stump pain of $6.1 \pm 1.5$ and 7.1 \pm 1.9 , respectively, and $6.1 \pm 2.1$ for phantom limb pain. After capsaicin $8 \%$ patch application, spontaneous pain, phantom and evoked pain scores all improved (Figure 3). At 4 weeks following patch application, the NPRS scores for spontaneous stump pain and evoked stump pain were

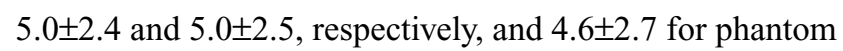
limb pain. The mean difference $(95 \% \mathrm{CI})$ for NPRS score, 4 weeks after application of capsaicin $8 \%$ patch, was -1.01 (0.12-1.89) for spontaneous stump pain $(p=0.028),-2.03$ $(0.63-3.4)$ for evoked stump pain $(p=0.007)$, and -1.41 $(0.27-2.5)$ for phantom limb pain $(p=0.018)$. Two patients reported complete resolution of phantom sensations after the treatment, and another reported a clear decrease in the duration of phantom limb pain episodes.

Patients also showed an improvement of the McGill pain score after capsaicin $8 \%$ patch application, with a mean difference $(95 \% \mathrm{CI})$ at the end of the follow-up of 11.0 (5.7-16.3) for continuous pain descriptors $(p=0.0006), 13.43$ (6.1-20.7) for intermittent pain descriptors $(p=0.002)$, and $10.3(3.5-17.1)$ for neuropathic pain descriptors $(p=0.005)$,

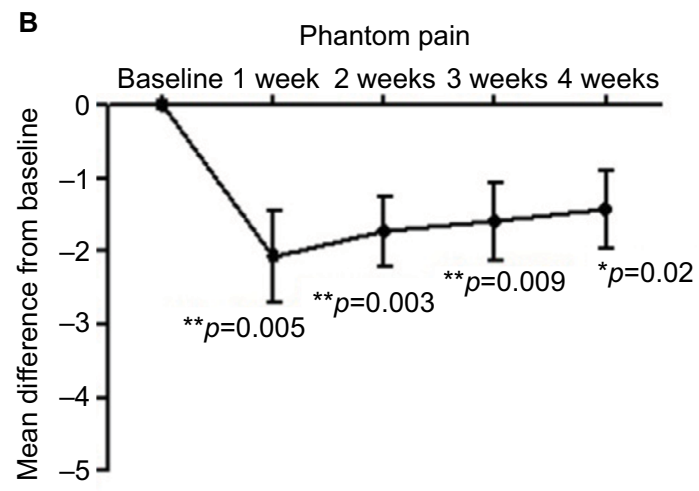

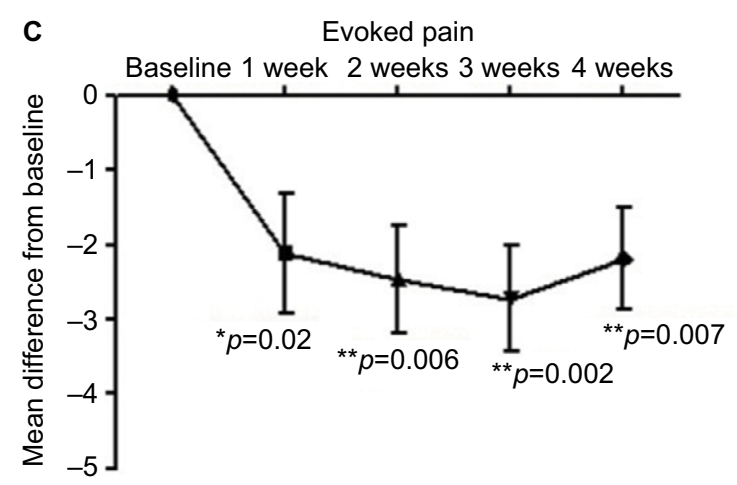

Figure 3 Pain scores at baseline and after capsaicin 8\% patch treatment.

Notes: Difference in pain scores over time from baseline for spontaneous stump pain (A), phantom limb pain (B), and evoked stump pain (C) in patients treated with capsaicin $8 \%$ patch. * Significant; ** very significant, *** highly significant. 
while the affective descriptors showed a relatively minor, but statistically significant change $(p=0.05)$, as shown in Figure 4. After capsaicin 8\% treatment, the Patient Global Impression of Change scale showed significantly marked improvement $(p=0.002)$.

\section{Quantitative sensory testing}

Sensory thresholds in the contralateral (intact) limb of all patients were within normal limits.

The tactile detection threshold (with monofilaments) in the amputation stump varied from reduced to elevated thresholds, the latter particularly in proximity of the scar tissue. All subjects but one reported brush dynamic allodynia. Pinprick sensation was also reported as increased in most cases, though five patients also described pinprick as decreased or absent in the areas of the stump near scar tissue.

After capsaicin $8 \%$ treatment, the area of allodynia for brush and hypersensitivity for pinprick showed a statistically significant decrease (Figures 5 and 6). The mean difference $(95 \% \mathrm{CI})$ at follow-up visit was $-65.6 \mathrm{~cm}^{2}(76.98-254.2)$ for brush mechanical allodynia $(p=0.001), 80 \%$ reduction, and $-132.2 \mathrm{~cm}^{2}(64.85-199.6)$ for pinprick hypersensitivity $(p=0.001), 72 \%$ reduction. No statistically significant changes in the area of monofilament static allodynia were observed after treatment.

A

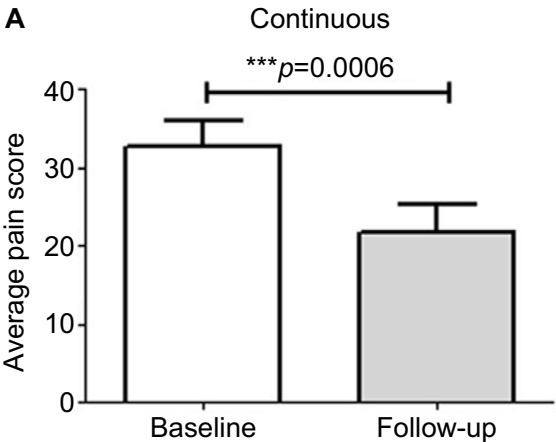

C

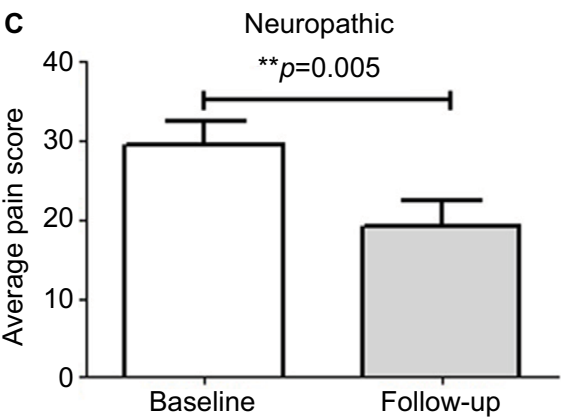

Vibration threshold tested at the amputation stump was within the normal limits in all but five patients. Four of these patients reported an elevated vibration threshold in the stump when compared to the homologous site in the intact limb, while in one patient, the vibration threshold was decreased compared to the contralateral side. These were not significantly changed after capsaicin $8 \%$ patch application.

At baseline, the mean difference in the stump from the contralateral limb for thermal thresholds was significantly elevated for cool $(p=0.0017)$ and warm $(p=0.0022)$ thresholds, but not for cold pain $(p=0.2907)$ or heat pain $(p=0.1788)$ thresholds. At follow-up, all patients showed a change with the trend toward normal values of the thermal thresholds except for two patients, while the cold and hot pain thresholds did not change. The patients who had an improvement of cool and warm thresholds showed a positive relationship between elevation of thermal thresholds at baseline and the magnitude of improvement after treatment (for cool: $r=0.73$, $p=0.0003$; for warm: $r=0.63, p=0.0007$ ).

\section{Functional magnetic resonance imaging}

Nine patients received fMRI scan before and after the treatment, as three patients had ferromagnetic objects potentially not compatible with the fMRI magnetic field, one patient

B

Intermittent

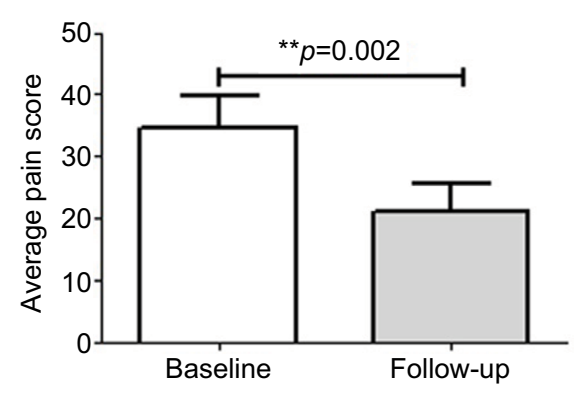

D

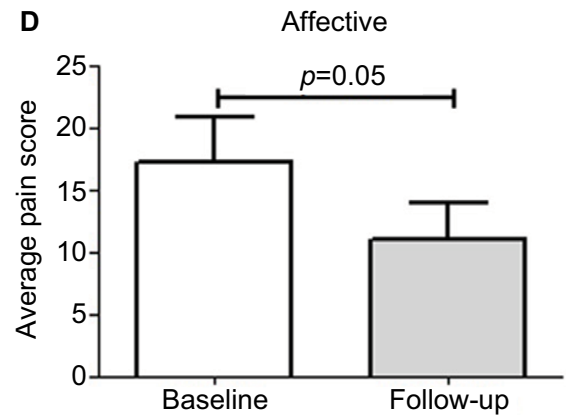

Figure 4 Short Form (SF) McGill pain score at baseline and end of study.

Notes: SF-McGill pain scores for continuous (A), intermittent (B), neuropathic (C), and affective (D) descriptors of pain in patients treated with capsaicin $8 \%$ patch, at baseline and after patch application. ** Very significant, *** highly significant. 

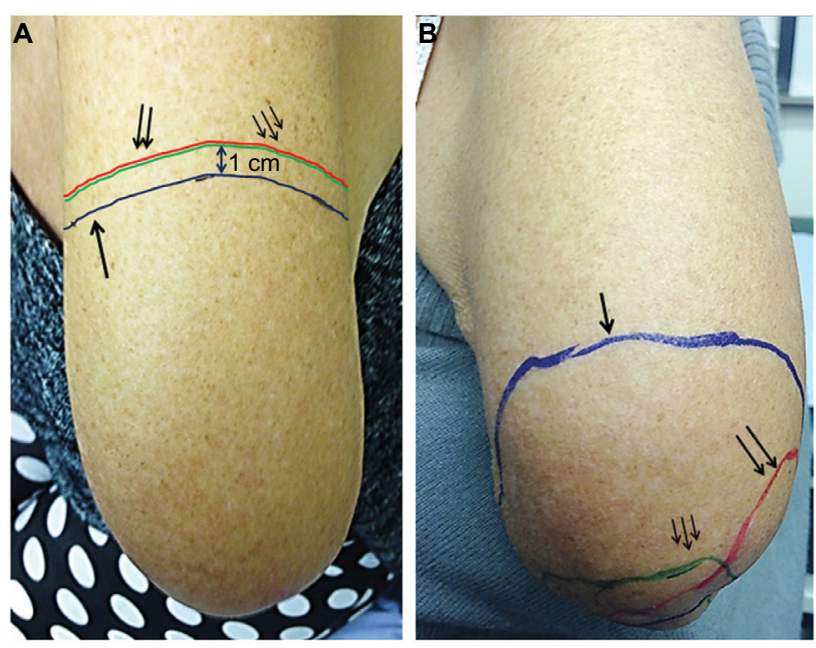

Figure 5 Amputation stump hypersensitivity in a patient before (A) and after (B) capsaicin $8 \%$ patch treatment.

Notes: Areas of mechanical dynamic allodynia (distal to green line), static allodynia (distal to red line), and pinprick hypersensitivity (distal to blue line) were found to be markedly decreased after treatment.

A Area of allodynia for brush

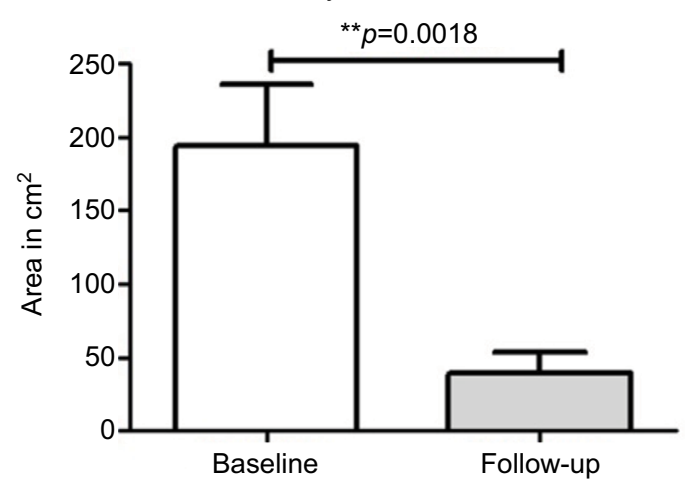

B

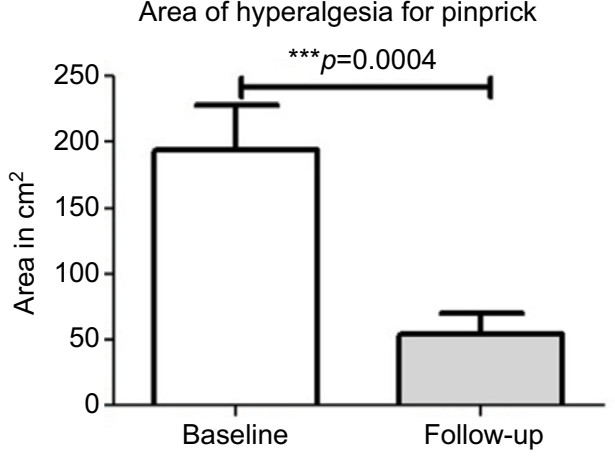

Figure 6 Areas of allodynia and hyperalgesia at baseline and end of study. Notes: Areas of mechanical dynamic allodynia (A) and pinprick hypersensitivity (B) in patients at baseline and after capsaicin $8 \%$ patch application. ** Very significant, *** highly significant.

was claustrophobic, and one patient was uncomfortable in keeping the supine position.

The effect of lip pursing $>$ rest averaged across both First and Second scans and across all patients and is shown in Figure 7. Analysis of data obtained in nine patients who completed the fMRI studies showed objective evidence of
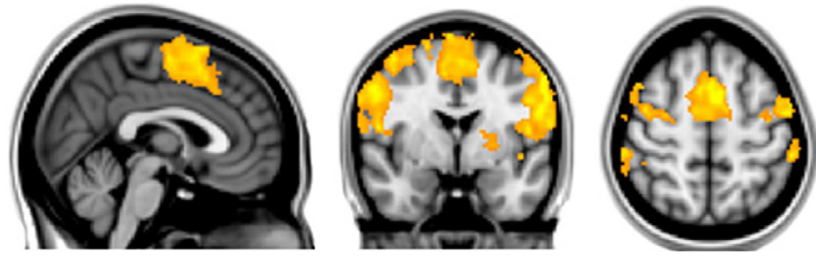

Figure 7 Effect of lip pursing > rest averaged across both First and Second scans and across all patients (whole-brain analysis using FSL with fixed effects, cluster corrected for multiple comparisons $p<0.05$ ).

Abbreviation: FSL, FMRIB Software Library.

restoration of brain maps with the lip pursing task. The difference between the scans (First $>$ Second scan) of lip pursing $>$ rest averaged across completed patients is shown in Figure 8, which indicates a decrease (reversal) of the spread into the hand representation area of the cerebral cortex with the lip pursing task (shown in green, arrowed).

\section{Discussion}

Our results demonstrate that a single 60 min capsaicin $8 \%$ patch application to the amputation stump is effective in reducing stump and phantom limb pain for 4 weeks, without any systemic or adverse events. We observed a marked decrease in the area of allodynia for brush and pinprick hypersensitivity in the amputation stump following capsaicin $8 \%$ patch treatment, which had beneficial consequences for using a prosthesis and, hence, for the mobility and rehabilitation of the patients. Current medical treatments for neuropathic pain have not been shown to be clearly effective in reducing post-amputation stump or phantom limb pain in clinical trials $^{33-36,70}$ and have side effects. ${ }^{71}$

Our findings are in accordance with previous observational studies, as of Kern et al, ${ }^{55}$ which reported relief of amputation stump and phantom limb pain in a small cohort of amputees after treatment with capsaicin $8 \%$ patch. In the larger QUEPP study, ${ }^{53,55} 30 \%$ of patients with phantom pain, $25 \%$ with stump pain, and $14 \%$ with combined phantom and stump pain experienced improvement in pain intensity after patch application.

Some authors have noted that amputees may find it difficult to distinguish between phantom and stump pain, while other studies have shown that amputees are able to differentiate stump pain from the phantom pain both immediately after the amputation ${ }^{72}$ and 1 year or more after the amputation. ${ }^{73}$ In our study, patients were asked, after careful explanation and demonstration, to rate spontaneous and evoked stump pain twice daily and phantom limb pain. The distinctions were reiterated at clinic visits, when touch and pinprick sensation were assessed, along with any allodynia or pinprick hypersensitivity. 

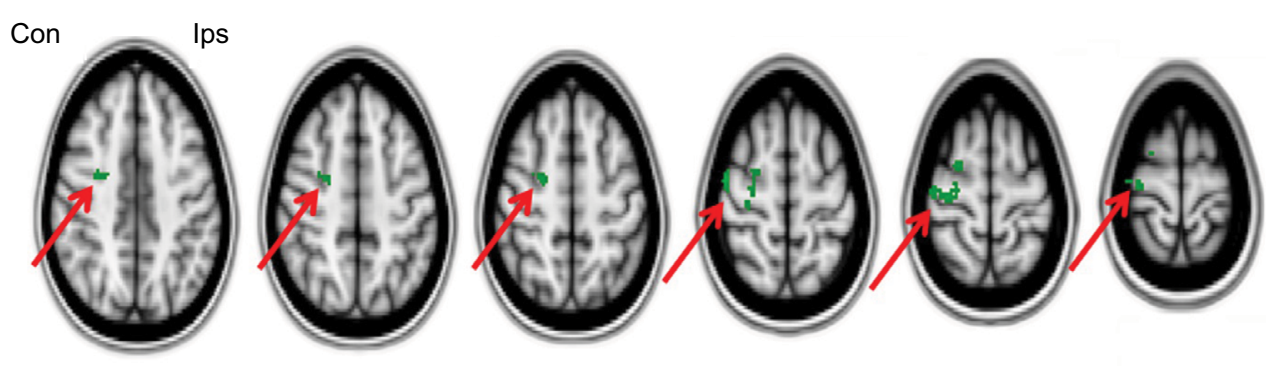

Figure 8 Difference between scans (First $>$ Second scan) of lip pursing > rest averaged across completed patients, showing a decrease (reversal) of the shift into the hand representation of the cerebral cortex with the lip pursing task (in green, arrowed). Images flipped so that left is contralateral to the amputation and right is ipsilateral (FSL with fixed effects, cluster corrected for multiple comparisons $p<0.05$ ).

Abbreviation: FSL, FMRIB Software Library.

Our findings were consistent with previous literature showing the coexistence in the residual limb of areas of hypoesthesia and hyperpathia for pinprick and light touch, ${ }^{66}$ often related to the proximity of the scar or grafted tissue..$^{65,74}$ In our study, amputees showed elevated thresholds for warm and cool perception in the residual but not intact limb, while no differences were found for cold and hot pain thresholds. Thermal thresholds for cool and warm in the residual limb showed a trend toward normal values after the treatment, which suggests regeneration or modification of the phenotype of nerve fibers and deserves further study. Previous studies indicated similar changes in thermal thresholds in the residual limb, ${ }^{65}$ though some showed differences such as decrease in cold threshold ${ }^{66}$ or increase in cold pain threshold. ${ }^{75,76}$ Electrical sensation and pain thresholds were found to be elevated in the residual limb in one study. ${ }^{75}$ The potential sources of differences include the presence of scar or grafted tissue and the site of testing, which may account for discrepant results.

To investigate the central mechanisms following treatment with capsaicin $8 \%$ patch in amputation stump and phantom limb pain, patients in our study were also assessed with fMRI scans. Amputees who reported relief from phantom limb pain showed a decrease in the spread of lip-to-hand representation in the cortex contralateral to the amputation stump, evoked during the lip pursing task. Further studies with larger numbers of subjects are needed to replicate this proof-of-concept study and upper versus lower limb amputation effects. Sensory stimulation, for example, by a pneumatic device, would also be of interest. ${ }^{24,26}$ As capsaicin $8 \%$ patch effects are restricted to cutaneous nerve terminals and are generally reversible, our findings suggest that phantom limb pain may be driven or modulated by peripheral inputs.

Using neuromagnetic source imaging, Flor et al showed shift in the contralateral cortex map of traumatic amputees who had phantom limb pain, ${ }^{24}$ but not in congenital amputees ${ }^{25}$ or healthy volunteers. ${ }^{26}$ The cortical reorganization was confirmed by Lotze et $\mathrm{al}^{27}$ and Maclver et $\mathrm{al}^{77}$ using fMRI in amputees who were asked to perform voluntary movements of the lips, intact hand, and imaginary movements of the phantom limb. Based on these results, the presence of phantom pain was attributed to an increased responsivity of the area of the brain representing the body part removed, due to the spatial invasion of adjacent cortical representations. However, Raffin et al ${ }^{78,79}$ reported that distinct and separate brain networks are activated by active or imagined movements, and these networks are similar between amputees and healthy controls. The preservation of the connections between cortex and periphery has been largely supported by Makin et al ${ }^{80-83}$ in amputees. An integrative explanatory hypothesis for the mechanisms responsible for generating phantom pain suggests the potential of coexistence between reorganizational processes of the cortex with the expansion of cortical map neighboring the deafferented area and the abnormal spontaneous activity of the area now deprived of peripheral input. ${ }^{84}$ The maladaptive plasticity and persistent representation models may be not mutually exclusive. ${ }^{85,86}$

As suggested by two studies, ${ }^{28,29}$ a normal cortical map representation may be restored in amputees by intervention at peripheral sites, as in our study. In these studies, both reimplantation of the missing limb and retargeting of peripheral terminals led to a large shift of cortical maps toward the expected preamputation location. Interestingly, the patient who had the transplant of both hands showed a reversal of the reorganization in a manner suggesting strengthening of preexisting connections. However, mirror therapy and mental imagery that work directly on the central nervous system have been shown to have beneficial effects with cortical remapping; thus, both central and peripheral inputs are important. ${ }^{77,87,88}$

\section{Conclusion}

This study showed marked relief of amputation stump pain and, particularly, the area of hypersensitivity following capsaicin $8 \%$ patch application. The treatment may enable patients to wear prostheses, thereby improving mobility and rehabilitation. fMRI scan analyses provided objective evidence of the restoration brain maps, thereby demonstrating 
that phantom limb pain ("central" pain) may be modulated by peripheral inputs and can be reduced by the peripherally restricted effect of the capsaicin $8 \%$ patch.

\section{Acknowledgments}

We are grateful to the Grace Anderson Trust, Edinburgh, the RNOH Charity, Stanmore and Astellas UK for financial support and helpful discussions.

\section{Authors' contributions}

RP, MS, IRM, and PA helped recruit patients and conducted the clinical study, RL set up and analyzed the fMRI scans, $\mathrm{RB}$ and PA conceived the study, and all authors contributed to the manuscript. All authors contributed toward data analysis, drafting and revising the paper and agree to be accountable for all aspects of the work.

\section{Disclosure}

PA has received speaker fees for symposia and meetings organized by Astellas UK, but no remuneration for this investigator-led study. The authors report no conflicts of interest in this work.

\section{References}

1. Ephraim PL, Wegener ST, MacKenzie EJ, Dillingham TR, Pezzin LE. Phantom pain, residual limb pain, and back pain in amputees: results of a national survey. Arch Phys Med Rehabil. 2005;86(10):1910-1919.

2. Ehde DM, Czerniecki JM, Smith DG, et al. Chronic phantom sensations, phantom pain, residual limb pain, and other regional pain after lower limb amputation. Arch Phys Med Rehabil. 2000;81(8):1039-1044.

3. Kern U, Busch V, Rockland M, Kohl M, Birklein F. [Prevalence and risk factors of phantom limb pain and phantom limb sensations in Germany. A nationwide field survey]. Schmerz.2009;23(5):479-488. German.

4. Finger S, Hustwit MP. Five early accounts of phantom limb in context: Paré, Descartes, Lemos, Bell, and Mitchell. Neurosurgery. 2003;52(3):675-686.

5. Dijkstra PU, Rietman JS, Geertzen JH. Phantom breast sensations and phantom breast pain: a 2-year prospective study and a methodological analysis of literature. Eur J Pain. 2007;11(1):99-108.

6. Ramesh, Shukla NK, Bhatnagar S. Phantom breast syndrome. Indian J Palliative Care. 2009;15(2):103-107.

7. Ramachandran VS, McGeoch PD. Occurrence of phantom genitalia after gender reassignment surgery. Med Hypotheses. 2007;69(5):1001-1003.

8. Pühse G, Wachsmuth JU, Kemper S, Husstedt IW, Kliesch S, Evers S. Phantom testis syndrome: prevalence, phenomenology and putative mechanisms. Int J Androl. 2010;33(1):e216-e220.

9. Ovesen P, Krøner K, Ornsholt J, Bach K. Phantom-related phenomena after rectal amputation: prevalence and clinical characteristics. Pain. 1991;44(3):289-291.

10. Arose B, Shreeve WW, Baim RS, Atkins HL. Phantom gallbladder. A variant of the rim sign. Clin Nucl Med. 1987;12(6):457-460.

11. Marbach JJ, Raphael KG. Phantom tooth pain: a new look at an old dilemma. Pain Med. 2000;1(1):68-77.

12. Sicuteri F, Nicolodi M, Fusco BM, Orlando S. Idiopathic headache as a possible risk factor for phantom tooth pain. Headache. 1991;31(9):577-581.

13. Whyte AS, Niven CA. Psychological distress in amputees with phantom limb pain. J Pain Symptom Manage. 2001;22(5):938-946.
14. Desmond DM, MacLachlan M. Affective distress and amputationrelated pain among older men with long-term, traumatic limb amputations. J Pain Symptom Manage. 2006;31(4):362-368.

15. van der Schans CP, Geertzen JH, Schoppen T, Dijkstra PU. Phantom pain and health-related quality of life in lower limb amputees. J Pain Symptom Manage. 2002;24(4):429-436.

16. Geertzen JH, Bosmans JC, van der Schans CP, Dijkstra PU. Claimed walking distance of lower limb amputees. Disabil Rehabil. 2005;27(3):101-104.

17. Raichle KA, Hanley MA, Molton I, et al. Prosthesis use in persons with lower- and upper-limb amputation. $J$ Rehabil Res Dev. 2008;45(7):961-972.

18. Bosmans JC, Geertzen JH, Post WJ, van der Schans CP, Dijkstra PU. Factors associated with phantom limb pain: a 31/2-year prospective study. Clin Rehabil. 2010;24(5):444-453.

19. Nikolajsen L, Ilkjaer S, Krøner K, Christensen JH, Jensen TS. The influence of preamputation pain on postamputation stump and phantom pain. Pain. 1997;72(3):393-3405.

20. Hanley MA, Jensen MP, Smith DG, Ehde DM, Edwards WT, Robinson LR. Preamputation pain and acute pain predict chronic pain after lower extremity amputation. J Pain. 2007;8(2):102-109.

21. Margalit D, Heled E, Berger C, Katzir H. Phantom fighters: coping mechanisms of amputee patients with phantom limb pain: a longitudinal study. Open J Orthopaedics. 2013;03(07):300-305.

22. Montoya P, Larbig W, Grulke N, Flor H, Taub E, Birbaumer N. The relationship of phantom limb pain to other phantom limb phenomena in upper extremity amputees. Pain. 1997;72(1-2):87-93.

23. Dijkstra PU, Geertzen JH, Stewart R, van der Schans CP. Phantom pain and risk factors: a multivariate analysis. J Pain Symptom Manage. 2002;24(6):578-585.

24. Flor H, Elbert T, Knecht S, et al. Phantom-limb pain as a perceptual correlate of cortical reorganization following arm amputation. Nature. 1995;375(6531):482-484.

25. Flor H, Elbert T, Mühlnickel W, Pantev C, Wienbruch C, Taub E. Cortical reorganization and phantom phenomena in congenital and traumatic upper-extremity amputees. Exp Brain Res. 1998;119(2): 205-212.

26. Knecht S, Henningsen H, Elbert T, et al. Reorganizational and perceptional changes after amputation. Brain. 1996;119(Pt 4):1213-1219.

27. Lotze M, Flor H, Grodd W, Larbig W, Birbaumer N. Phantom movements and pain. An fMRI study in upper limb amputees. Brain. 2001;124(Pt 11):2268-2677.

28. Chen A, Yao J, Kuiken T, Dewald JP. Cortical motor activity and reorganization following upper-limb amputation and subsequent targeted reinnervation. Neuroimage Clin. 2013;3:498-506.

29. Giraux P, Sirigu A, Schneider F, Dubernard JM. Cortical reorganization in motor cortex after graft of both hands. Nat Neurosci. 2001;4(7):691-692.

30. Huse E, Larbig W, Flor H, Birbaumer N. The effect of opioids on phantom limb pain and cortical reorganization. Pain. 2001;90(1-2): $47-55$.

31. Alviar MJ, Hale T, Dungca M. Pharmacologic interventions for treating phantom limb pain. Cochrane Database Syst Rev. 2016;10: CD006380.

32. Maier C, Dertwinkel R, Mansourian N, et al. Efficacy of the NMDAreceptor antagonist memantine in patients with chronic phantom limb pain--results of a randomized double-blinded, placebo-controlled trial. Pain. 2003;103(3):277-283.

33. Bone M, Critchley P, Buggy DJ. Gabapentin in postamputation phantom limb pain: a randomized, double-blind, placebo-controlled, cross-over study. Reg Anesth Pain Med. 2002;27(5):481-486.

34. Smith DG, Ehde DM, Hanley MA, et al. Efficacy of gabapentin in treating chronic phantom limb and residual limb pain. J Rehabil Res Dev. 2005;42(5):645-654.

35. Robinson LR, Czerniecki JM, Ehde DM, et al. Trial of amitriptyline for relief of pain in amputees: results of a randomized controlled study. Arch Phys Med Rehabil. 2004;85(1):1-6. 
36. Wilder-Smith CH, Hill LT, Laurent S. Postamputation pain and sensory changes in treatment-naive patients: characteristics and responses to treatment with tramadol, amitriptyline, and placebo. Anesthesiology. 2005;103(3):619-628.

37. Mou J, Paillard F, Turnbull B, Trudeau J, Stoker M, Katz NP. Efficacy of Qutenza ${ }^{\circledR}$ (capsaicin) $8 \%$ patch for neuropathic pain: a meta-analysis of the Qutenza Clinical Trials Database. Pain. 2013;154(9):1632-1639.

38. Brown S, Simpson DM, Moyle G, et al. NGX-4010, a capsaicin $8 \%$ patch, for the treatment of painful HIV-associated distal sensory polyneuropathy: integrated analysis of two phase III, randomized, controlled trials. AIDS Res Ther. 2013;10(1):5.

39. Irving GA, Backonja MM, Dunteman E; for NGX-4010 C117 Study Group. A multicenter, randomized, double-blind, controlled study of NGX-4010, a high-concentration capsaicin patch, for the treatment of postherpetic neuralgia. Pain Med. 2011;12(1):99-109.

40. Simpson DM, Brown S, Tobias J; for NGX-4010 C107 Study Group. Controlled trial of high-concentration capsaicin patch for treatment of painful HIV neuropathy. Neurology. 2008;70(24):2305-2313.

41. Webster LR, Malan TP, Tuchman MM, Mollen MD, Tobias JK, Vanhove GF. A multicenter, randomized, double-blind, controlled dose finding study of NGX-4010, a high-concentration capsaicin patch, for the treatment of postherpetic neuralgia. J Pain. 2010;11(10):972-982.

42. Babbar S, Marier JF, Mouksassi MS, et al. Pharmacokinetic analysis of capsaicin after topical administration of a high-concentration capsaicin patch to patients with peripheral neuropathic pain. Ther Drug Monit. 2009;31(4):502-510.

43. Backonja M, Wallace MS, Blonsky ER; for NGX-4010 C116 Study Group. NGX-4010, a high-concentration capsaicin patch, for the treatment of postherpetic neuralgia: a randomised, double-blind study. Lancet Neurol. 2008;7(12):1106-1112.

44. Backonja MM, Malan TP, Vanhove GF; for C102/106 Study Group. NGX-4010, a high-concentration capsaicin patch, for the treatment of postherpetic neuralgia: a randomized, double-blind, controlled study with an open-label extension. Pain Med. 2010;11(4):600-6008.

45. Mou J, Paillard F, Turnbull B, Trudeau J, Stoker M, Katz NP. Qutenza (capsaicin) 8\% patch onset and duration of response and effects of multiple treatments in neuropathic pain patients. Clin J Pain. 2014;30(4):286-294.

46. Simpson DM, Gazda S, Brown S, for NGX-4010 C118 Study Group. Long-term safety of NGX-4010, a high-concentration capsaicin patch, in patients with peripheral neuropathic pain. J Pain Symptom Manage. 2010;39(6):1053-1064.

47. Simpson DM, Brown S, Tobias JK; for NGX-4010 C107 Study Group NGX-4010, a capsaicin $8 \%$ dermal patch, for the treatment of painful HIV-associated distal sensory polyneuropathy: results of a 52-week open-label study. Clin J Pain. 2014;30(2):134-142.

48. Wagner T, Roth-Daniek A, Sell A, England J, Kern KU. Capsaicin $8 \%$ patch for peripheral neuropathic pain: review of treatment best practice from "real-world" clinical experience. Pain Manage. 2012;2(3):239-250.

49. Webster LR, Peppin JF, Murphy FT, Tobias JK, Vanhove GF. Tolerability of NGX-4010, a capsaicin $8 \%$ patch, in conjunction with three topical anesthetic formulations for the treatment of neuropathic pain. $J$ Pain Res. 2012;5:7-13.

50. Webster LR, Peppin JF, Murphy FT, Lu B, Tobias JK, Vanhove GF. Efficacy, safety, and tolerability of NGX-4010, capsaicin $8 \%$ patch, in an open-label study of patients with peripheral neuropathic pain. Diabetes Res Clin Pract. 2011;93(2):187-197.

51. Webster LR, Nunez M, Tark MD, et al. Tolerability of NGX-4010, a capsaicin $8 \%$ dermal patch, following pretreatment with lidocaine $2.5 \%$ / prilocaine $2.5 \%$ cream in patients with post-herpetic neuralgia. $B M C$ Anesthesiol. 2011;11:25.

52. Maihöfner CG, Heskamp ML. Treatment of peripheral neuropathic pain by topical capsaicin: impact of pre-existing pain in the QUEPP-study. Eur J Pain. 2014;18(5):671-679.
53. Maihofner C, Heskamp ML. Prospective, non-interventional study on the tolerability and analgesic effectiveness over 12 weeks after a single application of capsaicin 8\% cutaneous patch in 1044 patients with peripheral neuropathic pain: first results of the QUEPP study. Curr Med Res Opin. 2013;29(6):673-683.

54. Anand P, Bley K. Topical capsaicin for pain management: therapeutic potential and mechanisms of action of the new high-concentration capsaicin 8\% patch. Br J Anaesth. 2011;107(4):490-502.

55. Kern KU, Baust H, Hofmann W, Holzmüller R, Maihöfner C, Heskamp ML. [Capsaicin 8\% cutaneous patches for phantom limb pain. Results from everyday practice (non-interventional study)]. Schmerz. 2014;28(4):374-383. German.

56. Melzack R. The short-form McGill Pain Questionnaire. Pain. 1987;30(2):191-197.

57. Ferguson L, Scheman J. Patient global impression of change scores within the context of a chronic pain rehabilitation program. J Pain. 2009;10(4 Suppl):S73.

58. Hurst $\mathrm{H}$, Bolton J. Assessing the clinical significance of change scores recorded on subjective outcome measures. J Manipulative Physiol Ther. 2004;27(1):26-35.

59. Atherton DD, Facer P, Roberts KM, et al. Use of the novel Contact Heat Evoked Potential Stimulator (CHEPS) for the assessment of small fibre neuropathy: correlations with skin flare responses and intra-epidermal nerve fibre counts. BMC Neurol. 2007; $7: 21$.

60. Coppini DV, Wellmer A, Weng C, Young PJ, Anand P, Sönksen PH. The natural history of diabetic peripheral neuropathy determined by a 12 year prospective study using vibration perception thresholds. $J$ Clin Neurosci. 2001;8(6):520-524

61. Kloth LC, Feedar JA. Acceleration of wound healing with high voltage, monophasic, pulsed current. Phys Ther. 1988;68(4):503-538.

62. Bohannon RW, Pfaller BA. Documentation of wound surface area from tracings of wound perimeters. Clinical report on three techniques. Phys Ther. 1983;63(10):1622-1624.

63. Wellmer A, Misra VP, Sharief MK, Kopelman PG, Anand P. A doubleblind placebo-controlled clinical trial of recombinant human brainderived neurotrophic factor (rhBDNF) in diabetic polyneuropathy. $J$ Peripher Nerv Syst. 2001;6(4):204-210.

64. Anand P, Terenghi G, Warner G, Kopelman P, Williams-Chestnut RE, Sinicropi DV. The role of endogenous nerve growth factor in human diabetic neuropathy. Nat Med. 1996;2(6):703-707.

65. Hunter JP, Katz J, Davis KD. Dissociation of phantom limb phenomena from stump tactile spatial acuity and sensory thresholds. Brain. 2005; 128(Pt 2):308-320.

66. Harden RN, Gagnon CM, Khan A, Wallach G, Zereshki A. Hypoesthesia in the distal residual limb of amputees. PM R. 2010;2(7):607-611.

67. Jenkinson M, Beckmann CF, Behrens TE, Woolrich MW, Smith SM. FSL. Neuroimage. 2012;62(2):782-790.

68. Smith SM. Fast robust automated brain extraction. Hum Brain Mapp. 2002;17(3):143-155.

69. Jenkinson M, Bannister P, Brady M, Smith S. Improved optimization for the robust and accurate linear registration and motion correction of brain images. Neuroimage. 2002;17(2):825-841.

70. Wiech K, Kiefer RT, Töpfner S, et al. A placebo-controlled randomized crossover trial of the N-methyl-D-aspartic acid receptor antagonist, memantine, in patients with chronic phantom limb pain. Anesth Analg. 2004;98(2):408-413.

71. Wu CL, Agarwal S, Tella PK, et al. Morphine versus mexiletine for treatment of postamputation pain: a randomized, placebo-controlled, crossover trial. Anesthesiology. 2008;109(2):289-296.

72. Shukla GD, Sahu SC, Tripathi RP, Gupta DK. Phantom limb: a phenomenological study. Br J Psychiatry. 1982;141(1):54-58.

73. Schley MT, Wilms P, Toepfner S, et al. Painful and nonpainful phantom and stump sensations in acute traumatic amputees. J Trauma. 2008;65(4):858-864. 
74. Hunter JP, Katz J, Davis KD. Stability of phantom limb phenomena after upper limb amputation: a longitudinal study. Neuroscience. 2008;156(4):939-949.

75. Li S, Melton DH, Li S. Tactile, thermal, and electrical thresholds in patients with and without phantom limb pain after traumatic lower limb amputation. J Pain Res. 2015;8:169-174.

76. Wahren LK. Changes in thermal and mechanical pain thresholds in hand amputees. A clinical and physiological long-term follow-up. Pain. 1990;42(3):269-277.

77. Maclver K, Lloyd DM, Kelly S, Roberts N, Nurmikko T. Phantom limb pain, cortical reorganization and the therapeutic effect of mental imagery. Brain. 2008;131(Pt 8):2181-2191.

78. Raffin E, Mattout J, Reilly KT, Giraux P. Disentangling motor execution from motor imagery with the phantom limb. Brain. 2012;135(Pt 2):582-595.

79. Raffin E, Richard N, Giraux P, Reilly KT. Primary motor cortex changes after amputation correlate with phantom limb pain and the ability to move the phantom limb. Neuroimage. 2016;130:134-144.

80. Makin TR, Filippini N, Duff EP, Henderson Slater D, Tracey I, Johansen-Berg H. Network-level reorganisation of functional connectivity following arm amputation. Neuroimage. 2015;114: $217-225$.
81. Makin TR, Scholz J, Filippini N, Henderson Slater D, Tracey I, JohansenBerg H. Phantom pain is associated with preserved structure and function in the former hand area. Nat Commun. 2013;4:1570.

82. Makin TR, Wilf M, Schwartz I, Zohary E. Amputees "neglect" the space near their missing hand. Psychol Sci. 2010;21(1):55-57.

83. Makin TR, Scholz J, Henderson Slater D, Johansen-Berg H, Tracey I. Reassessing cortical reorganization in the primary sensorimotor cortex following arm amputation. Brain. 2015;138(Pt 8):2140-2146.

84. Boström KJ, de Lussanet MH, Weiss T, Puta C, Wagner H. A computational model unifies apparently contradictory findings concerning phantom pain. Sci Rep. 2014;4:5298.

85. Kuner R, Flor H. Structural plasticity and reorganisation in chronic pain. Nat Rev Neurosci. 2016;18(1):20-30.

86. Makin TR, Bensmaia SJ. Stability of sensory topographies in adult cortex. Trends Cogn Sci. 2017;21(3):195-204.

87. Barbin J, Seetha V, Casillas JM, Paysant J, Perennou D. The effects of mirror therapy on pain and motor control of phantom limb in amputees: a systematic review. Ann Phys Rehabil Med. 2016;59S:e149.

88. Diers M, Christmann C, Koeppe C, Ruf M, Flor H. Mirrored, imagined and executed movements differentially activate sensorimotor cortex in amputees with and without phantom limb pain. Pain. 2010;149(2):296-304.
Journal of Pain Research

\section{Publish your work in this journal}

The Journal of Pain Research is an international, peer reviewed, open access, online journal that welcomes laboratory and clinical findings in the fields of pain research and the prevention and management of pain. Original research, reviews, symposium reports, hypothesis formation and commentaries are all considered for publication.

\section{Dovepress}

The manuscript management system is completely online and includes a very quick and fair peer-review system, which is all easy to use. Visit http://www.dovepress.com/testimonials.php to read real quotes from published authors. 